\title{
LITERATURA E RESISTÊNCIA: MEMÓRIAS DA DITADURA CIVIL-MILITAR BRASILEIRA EM “K.: RELATO DE UMA BUSCA"
}

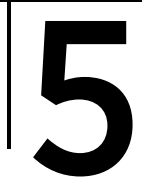

\section{LITERATURE AND RESISTANCE: MEMORIES OF THE CIVIL-MILITARY DICTATORSHIP IN “K.: RELATO DE UMA BUSCA"}

\section{POTT, Airton}

Mestre em letras pela UPF - Universidade de Passo Fundo

Doutorando em letras pela UPF - Universidade de Passo Fundo

E-mail: airton_pott@yahoo.com.br

ORCID ID: https://orcid.org/0000-0002-9809-1320

\section{TROMBETTA, Gerson Luis}

Doutor em Filosofia pela Pontifícia Universidade Católica do Rio Grande do Sul (PUCRS) com pós-doutorado em Filosofia pela Universidade Federal de Minas Gerais. Professor da UPF Universidade de Passo Fundo

E-mail: gersont@upf.br

ORCID ID: https://orcid.org/0000-0001-8607-2029

\section{AQUINO, Ivânia Campigotto}

Doutora em Letras - Estudos de Literatura pela Universidade Federal do Rio Grande do Sul com pós-doutorado em Letras - Estudos de Literatura pela Universidade Federal do Rio Grande do Sul Professora da Universidade de Passo Fundo

E-mail: ivania@upf.br

ORCID ID: orcid.org/0000-0001-9221-3473

\section{RESUMO}

A literatura se tornou uma forma de inúmeros autores que escrevem sobre a ditadura civil-militar brasileira resgatarem e representarem suas memórias, bem como as de familiares, amigos e demais vítimas desse período. K.: relato de uma busca, escrito por Bernardo Kucinski, é uma dessas obras literárias e guarda em si vários traços verossimilhantes com a realidade vivida pelo autor, e também pelo seu pai e sua irmã Ana Rosa, desaparecida durante a ditadura civil-militar brasileira. Considerando esse contexto, almeja-se verificar como essas memórias estão registradas na narrativa K.: relato de uma busca e como leitores se manifestam em diferentes meios de circulação digital a respeito desses aspectos da obra. Para realizarmos tais estudos ancoramo-nos nas teorias de Ricoeur (2007), Gagnebin (1999, 2006), Figueiredo (2017), Fico (2004) e Bezerra (2014) a respeito de conceitos relacionados à memória, esquecimento e demais termos condizentes ao tema que elencamos para nossas investigações, as 
quais nos permitem compreender sobre o papel da literatura no processo de rememoração de episódios acontecidos nesse passado sombrio.

Palavras-chave: Memórias. Esquecimento. Ditadura civil-militar. Literatura. Narrativa(s).

\section{ABSTRACT}

Literature has become a way for countless authors who write about the Brazilian military dictatorship to rescue their memories, as well as those of family members, friends and other victims of that period. $K$.: relato de uma busca, written by Bernardo Kucinski, is one of these countless literary works and has in itself numerous credible traces with the reality experienced by the author, and especially his father and sister Ana Rosa, who disappeared during the military dictatorship. Given this context, the aim is to verify how these memories are registered in the narrative $K$.: relato de uma busca and how different readers manifest themselves in different means of digital circulation regarding these aspects of the work. To carry out such studies, we anchored in studies by Ricoeur (2007), Gagnebin (1999, 2006), Figueiredo (2017), Fico (2004) and Bezerra (2014) about concepts related to memory, forgetting and other concepts related to theme that we listed for our investigations, which allow us to conclude about the important role of literature in this process of remembering episodes that happened in the past.

KEYWORDS: Memories. Forgetting. Civil-military dictatorship. Literature. Narrative(s).

\section{INTRODUÇÃO}

A literatura contemporânea, devido ao seu caráter ficcional, imaginário e libertador, tornou-se o lugar e o refúgio para muitos autores registrarem suas memórias mais difíceis, como é o caso de Bernardo Kucinski. Autor de K.: relato de uma busca ${ }^{1}$, Kucinski narra a trajetória de um protagonista que não tem seu nome revelado, apenas denominado pela inicial K., um pai que busca incansavelmente sua filha desaparecida durante o período da ditadura militar brasileira.

Muitos são os indícios que revelam semelhanças de episódios narrados em $K_{\text {.: }}$ relato de uma busca com os acontecimentos da vida de Bernardo Kucinski e sua família. Entretanto, nosso objetivo não é

1. K.: relato de uma busca foi publicado pela primeira vez em 2011 pela editora Expressão Popular, em 2013 pela Cosac Naify e em 2016 pela Companhia das Letras, sendo que consideramos esta última para nossos estudos. 
investigar o caráter autobiográfico da obra, mas sim como estas memórias são representadas na narrativa e quais são as percepções de leitores que se manifestaram por meio de textos e/ou comentários em diferentes veículos de circulação digital².

Para a construção dos argumentos a serem expostos aqui, visitamos, primeiramente, os conceitos de memória e esquecimento. Servem como base, para tanto, autores como Ricoeur (2007), Gagnebin (1999, 2006), Figueiredo (2017), Fico (2004) e Bezerra (2014). Também tecemos uma breve retomada teórica sobre a importância da ficção e da literatura contemporânea para a realização da representação das memórias. Por fim, analisamos textos e comentários de leitores de $K$.: relato de uma busca, amparados nos conceitos teóricos e sobretudo no caráter de resistência contra o esquecimento, intencionado pelo autor Bernardo Kucinski.

\section{MEMÓRIA E ESQUECIMENTO: TENSÕES E NECESSIDADES}

Quando nos deparamos com as memórias a respeito de um período histórico traumático e ainda acompanhado de "tabus", como é o caso da ditadura civil-militar brasileira, possivelmente vamos encontrar também aqueles que lutam para que o ocorrido não seja esquecido e se torne de conhecimento de um público maior. A "memória não se limita a guardar o rastro material, escrito ou outro, dos fatos acabados, mas entretém o sentimento de dever a outros." (RICOEUR, 2007, p. 101). Ou seja, a memória é voltada a um ou mais fatos passados, normalmente ligados a pessoas que não são necessariamente aquelas que vivenciaram tal período ou tais experiências rememoradas.

Muitas pessoas, por motivos ideológicos e por interesses difusos, vivem ainda hoje às sombras da ditadura civil-militar. Não é apenas na areia da praia ou em um chão molhado que ficam rastros, mas também nesses fatos históricos ocorridos, ainda mais tão obscuramente marcantes. "Rastro" é uma marca de algo que já passou, mas que deixou marcas, e, no caso da ditadura militar, elas estão presentes principalmente nas memórias. A fim de reforçarmos tais afirmações, recorremos a Gagnebin (2006, p. 44), que faz uma indagação a respeito da ligação da memória ao rastro e, já na sequência, procura respondê-la:

Porquea reflexãosobrea memóriautilizatãofrequentemente

a imagem - o conceito — de rastro? Porque a memória

2. Os leitores selecionados foram os que se manifestaram na Skoob, por ser a maior rede social dos leitores, e também de páginas e blogs de circulação literária a fim de contrastar os comentários destes públicos. 
vive essa tensão entre a presença e a ausência, presença do presente que se lembra do passado desaparecido, mas também presença do passado desaparecido que faz sua irrupção em um presente evanescente. Riqueza da memória, certamente, mas também fragilidade da memória e do rastro.

Quando pensamos na memória relacionada ao mais assombroso período brasileiro, podemos pensar, de imediato, que o golpe militar foi uma verdadeira urdidura tramada para conquistar interesses próprios. Fico (2004) corrobora que a conspiração é um dos elementos sobrelevados ligados ao golpe militar, um aspecto complexo que mobilizou esse processo histórico. Devido a isso, é natural que as vítimas da ditadura militar queiram que mais pessoas saibam sobre o que aconteceu naqueles anos e, assim, tentam externar aos demais o que elas guardam em suas memórias. Bezerra (2014, p. 37) propõe que "a percepção da memória como uma atividade interativa e social nos obriga a reconhecer que todo ato de rememorar implica um processo de recriação, reelaboração, ressignificação do passado tendo o momento presente como referência", o que nos leva para além das metodologias tradicionais da historiografia e abre campo para a literatura.

Inúmeros autores têm optado pelos romances ficcionais, vários inclusive autoficcionais ou autobiográficos a fim de externar suas memórias sobre a ditadura. Conforme Ricoeur (2007, p. 57), "o momento da recordação é então o do reconhecimento. Esse momento, por sua vez, pode percorrer todos os graus da rememoração tácita à memória declarativa, mais uma vez pronta para a narração". Convém ressaltar que, devido ao fato de a narração estar pronta para a declaração dos autores, estes, ao visitarem tal gênero, precisam adaptar-se às suas características a fim de conquistarem os receptores daquelas rememorações narradas os exigentes leitores: "ao escrever para um público mais amplo, o autor encontra no leitor um elemento ativo na transmissão da memória para que não se apague aquilo que afetou a vida das pessoas" (FIGUEIREDO, 2017, p. 46).

A memória passa a ser parte integrante e constitutiva de onde ela fará sua morada, o lugar onde ela será (re)criada. Dessa forma, "se a memória funciona como um marco na criação de um senso de pertencimento, é preciso lançar um olhar crítico sobre seu processo de criação e legitimização." (BEZERRA, 2014, p. 42). Ao pertencer à narração, a memória passa por um processo de transformação, uma 
metamorfose em que ela, através do seu guardador, passará a pertencer a outro, à história narrada. Na mesma linha, Gagnebin (1999, p. 92) sustenta que "é o fio da linguagem, às vezes entrecortado, às vezes rompido, o fio da história que nós narramos uns aos outros, a história que lembramos, também a que esquecemos e a que, tateantes, enunciamos hoje.".

Através da memória e da história registradas por intermédio da narração, podemos perceber o elemento tensionado do esquecimento. Ele surge como duelista contra a memória e causa inquietações, que partem de premissas básicas, transformadas por Ricoeur (2007, p. 46) em duas perguntas norteadoras:

Buscamos aquilo que tememos ter esquecido, provisoriamente ou para sempre, com base na experiência ordinária da recordação, sem que possamos decidir entre duas hipóteses a respeito da origem do esquecimento: trata-se de um apagamento definitivo dos rastros do que foi aprendido anteriormente, ou de um impedimento provisório, este mesmo eventualmente superável, oposto à sua reanimação? Essa incerteza quanto à natureza profunda do esquecimento dá à busca o seu colorido inquieto. Quem busca não encontra necessariamente.".

Ao analisarmos a dinâmica da memória nos deparamos necessariamente com o esquecimento, posto que é impossível lembrarmos de absolutamente tudo, e o medo de esquecer cada vez mais causa frustração e inquietação aos possuidores da memória. Como sugere Figueiredo (2017, p. 102), "a memória funciona, antes, como fluxos de imagens que vêm para a superfície da consciência, às vezes de maneira desconexa, às vezes na forma de uma inquietação cuja causa se desconhece" (FIGUEIREDO, 2017, p. 102).

Memórias são, muitas vezes, dispersas, cujos donos delas podem não ter completo domínio e certeza de tudo o que viveram naquela época e tentam externar tais lembranças agora, na contemporaneidade, para o romance, por exemplo, que é o caso de nossas investigações aqui delineadas. Temos, então, dois vieses do esquecimento em um confronto estabelecido na mente do rememorador: "Contra o esquecimento destruidor, o esquecimento que preserva" (RICOEUR, 2007, p. 449).

Em outras palavras, como existe o esquecimento, onde a memória é apagada, as lembranças e os fatos podem ser esquecidos. Pelo fato de 
o rememorador saber que o esquecimento existe, o que é temeroso a ele, há a instigação também por essa circunstância para ele fazer registros, arquivamentos, com o propósito de que não ocorra a perda. Dessa forma, há também o esquecimento que preserva a memória dos fatos. Ou seja, é na escrita, ou outra forma de propagação das informações, que é dado "à memória os meios de combater o esquecimento." (RICOEUR, 2007, p. 449).

Quando a memória vence o esquecimento temos a propagação de tais recordações. Quando esquecidas, como eram portadas por apenas aquele sujeito, cessam imediatamente. Mas foquemos na memória, sobretudo revivida na narração, como forma de combate ao esquecimento. Destarte, o esquecimento seria "não só uma falha, um 'branco' de memória, mas também uma atividade que apaga, renuncia, recorta, opõe ao infinito da memória a finitude necessária da morte e a inscreve no âmago da narração." (GAGNEBIN, 1999, p. 03). Consideremos, também, o fato de que inúmeras são as memórias atreladas ao período da ditadura civil-militar, o que resulta, portanto, em uma memória coletiva, uma vez que as vítimas sofriam os mesmos métodos de perseguições, torturas e mortes, sendo que muitos familiares acabavam descobrindo pelo menos parte de tais rechaças. Ou então, as memórias poderiam ser rememoradas pelos sobreviventes torturados. Concordamos com Bezerra (2014, p. 36) quando afirma:

O tenso debate em torno da memória desse período pode ser mais bem compreendido quando temos em mente que a memória coletiva funciona como um quadro social constituído a partir de fatos, valores e crenças que servem de ponto de referência para os indivíduos e a sociedade como um todo.

O conjunto de memórias pode ser compreendido como um quadro social, uma vez que é um conjunto de vozes que rememora aqueles períodos traumáticos, ao mesmo tempo em que resgata valores e crenças. As vidas aniquiladas não voltam mais, mas a narração dessas memórias as honra e dignifica os vivos. Logo, "A memória é fundamental nesse tipo de romance, pois não existe uma memória única, um bloco que volta por inteiro." (FIGUEIREDO, 2017, p. 102). Afinal, não se trata apenas de memórias, mas também de um trauma coletivo que pode ser representado (e tratado) por meio das obras literárias. 


\section{A LITERATURA CONTEMPORÂNEA COMO GUARDADORA DE MEMÓRIAS}

A realidade dentro da ficção e a rememoração dos episódios ocorridos no período da ditadura civil-militar ocuparam amplo espaço na literatura contemporânea brasileira. Os escritores pretendem, por meio da escrita de tais narrações, perpassar aos leitores as suas memórias. Portanto, temos memórias e lembranças transmitidas pelo texto a muitas outras mentes, as quais as mantêm vivas e tendem a propagá-las também, colaborando com a sobrevivência das memórias das vítimas da ditadura civil-militar. De acordo com Ricoeur (2007, p. 98),

A memória é incorporada à constituição da identidade por meio da função narrativa. A ideologização da memória torna-se possível pelos recursos de variação oferecidos pelo trabalho de configuração narrativa. E como os personagens da narrativa são postos na trama simultaneamente à história narrada, a configuração narrativa contribui para modelar a identidade dos protagonistas da ação ao mesmo tempo que os contornos da própria ação.

O imaginário tanto do autor quanto do leitor é suscitado para avaliar a realidade dentro da ficção, bem como para despertar sentimentos e emoções, o que também é uma das finalidades do texto literário, ficcional. Os personagens são fatores decisivos na rememoração da realidade da ditadura na ficção, pois é com estes que o leitor vai se identificar. Como sugere Figueiredo (2017, p. 45), "a literatura, ao recriar o ambiente de tensão e de horror, provoca a identificação do leitor, suscita a emoção e a compreensão ao mesmo tempo.".

Além de despertar comoções no leitor, o texto ficcional instiga o imaginário para a compreensão e também para a identificação do passado da ditadura militar naquela narração. Dessa forma, "enquanto a imaginação pode jogar com entidades fictícias, quando ela não representa o real, mas se exila dele, a lembrança coloca as coisas do passado." (RICOEUR, 2007, p. 64). Interessante pensarmos no duplo imaginário que ronda o texto ficcional - o do autor, ao escrevê-lo, e o do leitor, que recorre ao imaginário para melhor compreender o que está sendo narrado. Conforme Figueiredo (2017, p. 45),

Só a literatura é capaz de suscitar a figuração do Outro, do diferente, aquele que não podemos conhecer se não sairmos de dentro de nós mesmos. Só através da literatura podemos vislumbrar o Outro que nos habita, porque a 
identidade só se perfaz no encontro com a alteridade, inclusive nossa própria alteridade.

Vislumbramos o Outro porque nos identificamos com ele. Ao interagirmos com o Outro, adquirimos características, informações e conhecimento deste. Dessa forma, podemos pensar no imaginário e no conhecimento possibilitados pelas narrativas ficcionais como dialogando com o tempo atual. Nas palavras de Ricoeur (2007, p. 394), "o discurso da preocupação é, em primeiro lugar, um discurso centrado no presente vivo".

Logo, as memórias do passado são voltadas ao presente devido ao fato de que, mesmo que ela possa modificar as concepções e as informações do passado, é no presente que as coisas acontecem. Além do que, a ficção determina uma infinita possibilidade de discursos por meio de suas estratégias e linguagem, o que reiteramos através de Figueiredo (2017, p. 44): “A ficção não é sinônimo de fantasia e de imaginação: trata-se, antes, de uma estratégia ordenadora da linguagem a fim de criar uma narrativa legível, compreensível".

Podemos pensar na ficção como instigadora do imaginário devido ao ato de o leitor interpretar o narrado. Quanto à narração, contudo, é preciso marcar um alerta: "assim como é impossível lembrar-se de tudo, é impossível narrar tudo. A ideia de narração exaustiva é uma ideia performativamente impossível. A narrativa comporta necessariamente uma dimensão seletiva." (RICOEUR, 2007, p. 455). Com relação aos acontecimentos relacionados à ditadura civil-militar, muito há para ser lembrado e narrado, mas nem tudo é possível. Logo, mediante o fato de não conseguir narrar tudo e nem lembrar de tudo, o autor seleciona o que deseja narrar conforme suas pretensões.

Ao concatenarmos a ficção à fantasia no ato de narrar, percebemos esta como uma capacidade inventiva, imaginativa, e aquela é uma criação, uma visão que torna a outra possível: "a ficção é parte intrínseca do ato de narrar, mas a fantasia só surge nas narrativas de valor testemunhal para exprimir as incongruências e as ironias do comportamento autoritário." (FIGUEIREDO, 2017, p. 45). A fantasia, de caráter testemunhal, está concatenada à memória, já que esta também é real, mediante o testemunho de alguém. Além do mais,

Na história, na educação, na filosofia, na psicologia o cuidado com a memória fez dela não só um objeto de estudo, mas também uma tarefa ética: nosso dever consistiria em preservar a memória, em salvar o desaparecido, o passado, 
em resgatar, como se diz, tradições, vidas, falas e imagens (GAGNEBIN, 2006, p. 97).

Em linhas gerais, a literatura foi, e ainda é - mesmo tendo como predomínio conceitual a ficção, o imaginário, o além do real -, uma forma que muitos escritores encontraram para rememorar o sofrimento das vítimas da ditadura instaurado por ela. Não restam dúvidas de que "nos últimos cinquenta anos, dos primeiros dias após o golpe de $1^{\circ}$ de abril de 1964 até o presente, escritores têm produzido todo tipo de texto, mas, sobretudo, narrativas, de cunho ficcional ou não ficcional, sobre os desmandos da ditadura." (FIGUEIREDO, 2017, p. 45).

Por trás dessas narrativas sobre a ditadura militar está também o inacessível ao leitor, pois não há narrativa que engloba tudo relacionado a esse período. Muito ficou no desconhecido, e, talvez, no indizível. Portanto, "a confissão de que, por trás da interpretação, subsiste sempre um fundo impenetrável, opaco, inesgotável de motivações pessoais e culturais, do qual o sujeito jamais acabou de dar conta." (RICOEUR, 2007 , p. 351). Acrescido a tais percepções, esse estudioso ainda adverte que

O reconhecimento do fato de que sempre é possível interpretar de outra forma o mais complexo e, portanto, a admissão de um grau inevitável de controvérsia, de conflito entre interpretações rivais; em seguida, a pretensão de dotar a interpretação assumida com argumentos plausíveis, possivelmente prováveis, submetidos à parte adversa. (RICOEUR, 2007, p. 351).

Com relação à rememoração da ditadura militar na ficção, mesmo com argumentos plausíveis e prováveis, "não se pode imaginar a restituição de 'toda a verdade' do acontecimento, porque o acontecimento pertence ao domínio do vivido e a escrita literária pertence ao domínio da linguagem." (FIGUEIREDO, 2017, p. 123). Assim como também "não se pode confundir o que se passa na vida real de cada um de nós com o que se lê num livro, são universos diferentes, com códigos diferentes, pois a realidade nos escapa sempre." (FIGUEIREDO, 2017, p. 123).

A tortura sofrida pelas vítimas da ditadura civil-militar, pela voz e visão delas e de seus familiares, é algo que ainda não é de conhecimento para muitos ou mesmo é um fenômeno negado. A literatura - e suas múltiplas abordagens - pode trazer à tona informações inesperadas e desconhecidas ao leitor, o que pode ir além do intencionado por este ou ser diferente de suas expectativas. Conforme verificamos em Ricoeur 
(2007, p. 290), que já fazia tais anunciações em seus estudos:

As formas narrativas ao dar à narrativa um fecho interno à intriga, tendem a produzir um efeito de enclausuramento, que não é menor quando o narrador, contrariando a expectativa do leitor, faz tudo para decepcionar este último por alguns estratagemas de não-enclausuramento

Diante da concepção de não-enclausuramento da narrativa elucubrada por Ricoeur (2007), concluímos que o leitor pode se sentir impactado com aquilo que não imaginava, com o inesperado. Entretanto, é justamente isso que acaba instigando o leitor a permanecer na leitura e, por sinal, muitas narrativas contemporâneas possuem estratagemas pensados pelo autor a fim de surpreender seu público tanto na forma de narrar e abordar os temas quanto na estrutura e composição da obra.

\section{MEMÓRIAS DE KUCINSKI EM K.: RELATO DE UMA BUSCA IDENTIFICA- DAS POR LEITORES}

K., o protagonista da narrativa $K .:$ relato de uma busca, guarda em seu nome, representado apenas pela letra inicial, possíveis mistérios, segredos, revelações e verossimilhanças com a realidade de muitas pessoas, sobretudo de seu autor, Bernardo Kucinski, e familiares dele. Logo, encontramos em K.: relato de uma busca um adequado objeto de estudo para analisarmos sobre a representatividade da memória sobre os acontecimentos na ditadura civil-militar brasileira.

Ao averiguarmos a obra K.: relato de uma busca e a compararmos com reportagens, entrevistas e outros canais virtuais de comunicação e informação, apuramos vários fatos oriundos das memórias do autor Bernardo Kucinski que foram rememoradas, guardadas e representadas em $K$.: relato de uma busca. Portanto, em meio a várias outras estratégias narrativas, Kucinski também conseguiu, em sua engenhosidade, resgatar muitas de suas memórias em sua obra narrativa, tornando-a uma forma de "arquivamento", para usar o termo de Figueiredo (2017).

Em uma entrevista à Taketani (2016, s. p.), publicada no Jornal Literário Suplemento Pernambuco, Bernardo Kucinski responde que "O pai em K. é uma fusão de personagens, eu entre eles. Esse foi o recurso principal que permitiu transportar a história para o domínio do ficcional, a despeito de seus conteúdos serem essencialmente factuais.". Fica explícito, assim, que o personagem principal de K.: relato de uma busca representa muitas pessoas que vivenciaram a realidade da ditadura civilmilitar brasileira, inclusive o próprio autor Bernardo Kucinski. 
Também Zillo (2017, s.p., grifos do autor) destaca sobre Bernardo Kucinski representar a si na obra $K$.: relato de uma busca quando afirma que "Muito desse sentimento vem do próprio autor Bernardo, por ter vivido durante a ditadura e ter perdido a própria irmã, presa pelos militares e dada como desaparecida na década de 1970. K. é, na verdade, a história de seu pai à procura da filha". Tal acontecimento é o cerne de muitos dos vinte e nove capítulos de K.: relato de uma busca.

A inserção de novos capítulos, personagens e outras vozes narrativas faz com que sejam trazidos outros elementos e aspectos relacionados a episódios da ditadura civil-militar brasileira, e consequentemente esta busca é interrompida várias vezes ao longo da narrativa. Do mesmo modo, temos a impressão, em alguns momentos no meio da narrativa, que a busca do pai pela filha desaparecida chega a um encerramento, como no final do capítulo 15, Imunidades, um paradoxo: "O pai que procurava a filha desaparecida já nada procura, vencido pela exaustão e pela indiferença. Já não empunha o mastro com a fotografia. Deixa de ser um ícone. Já não é mais nada. É o tronco inútil de uma árvore seca." (KUCINSKI, 2016, p. 85).

Este fato de K. ser caracterizado como alguém que está exausto, sem forças para prosseguir sua busca, possibilita ao leitor entender que a narrativa parece chegar ao fim, o que tende a causar certo estranhamento, já que isto ocorre no meio da narrativa. Entretanto, surgem novos elementos e novas pistas, que desconstroem a ideia de inutilidade da árvore seca, isto é, do velho pai esgotado. Afinal, muito há nas memórias desse pai incansável que representa inúmeras pessoas de realidades incongruentes no período da ditadura civil-militar.

Koehler (2012, s.p.), outro leitor de obras literárias de Bernardo Kucinski, afirma que K.: relato de uma busca "é um livro de ficção, mas quando se conhece a história de Kucinski, de seu pai e de sua irmã, percebe-se que a ficção foi a maneira encontrada pelo jornalista para expurgar muitos dos seus fantasmas pessoais.". Assim como o autor Bernardo Kucinski quis expurgar fantasmas da ditadura civil-militar que Ihe assombram, também o personagem $\mathrm{K}$. pretendia de diversas formas realizar algo que registrasse o que poderia ter acontecido com sua filha, já que não se sabe com precisão o que lhe aconteceu.

Dentre as formas de rememoração, de registrar as suas memórias e as de sua família, sobretudo de sua filha desaparecida, K. resolve escrever um livro em que registra os acontecimentos: "Desolado pela falta da matzeivá, ocorreu então a K. a ideia de compor um pequeno livrinho em memória da filha e do genro. Uma lápide na forma de livro. 
Um livro in memoriam." (KUCINSKI, 2016, p. 77-78, grifos do autor). Ao pensarmos que K.: relato de uma busca é um livro baseado em pessoas e acontecimentos do mundo real, sobretudo de Kucinski e seus familiares, arriscamos afirmar que esta obra pode ser considerada não só como narrativa, mas também a realização do livro in memoriam, ou pelo menos ser comparado a um.

Muitos dos resenhistas, pesquisadores e demais leitores que se manifestaram em veículos de circulação digital ressaltaram também sobre o fato de Ana Rosa Kucinski ter se casado, como é o caso de Casarin (s.d., s.p.) "Ana Rosa Kucinski e Wilson Silva desapareceram em 22 de abril de 1974. Militavam pela ALN (Ação Libertadora Nacional) e sumiram quando repressores eliminavam pessoas que pudessem comprometê-los de alguma forma. A bandidagem batia continência.".

Muitos leitores de K.: relato de uma busca fazem referência também ao casamento de Ana Rosa Kucinski e Wilson Silva. Afinal, ao longo da narrativa aparece a menção do casamento clandestino da filha de K., recebendo inclusive um capítulo em que se enfatiza sobre a união matrimonial, intitulado $O$ matrimônio clandestino justamente pelo fato de K. descobrir casualmente sobre o fato:

Quando aquela moça se aproximou na reunião dos familiares dos desaparecidos e se apresentou, eu sou a cunhada da sua filha, K. percebeu a vastidão da outra vida, oculta, da filha. Ela até se casara sem ele saber; tinha marido, uma cunhada, sogros. O marido também estava desaparecido. Mais esse susto no colar de tantos espantos, descobrir que outra família também chorava sua ausência, não como filha, como nora, e ele agora também teria que chorar uma segunda desaparição, a do genro, e mais, de netos que poderia ter, mas não terá - embora disso naquele momento ele ainda não soubesse. (KUCINSKI, 2016, p. 41).

Ao considerarmos o fragmento acima, que é o primeiro parágrafo do capítulo supracitado, percebemos que, na narrativa, K. descobriu casualmente sobre o casamento às escondidas de sua filha, o que, para ele, passa a ser mais um motivo de sofrimento, angústias e buscas, inclusive pelo fato de não saber se ele tem/teve netos. As cinco páginas desse capítulo são destinadas à narração sobre o casamento da filha de K. realizado secretamente e às investigações e reflexões de K. sobre o porquê de ela ter feito isso. Por fim, "depois de matutar muito, K. 
convenceu-se de que a única razão para se casarem formalmente, na situação de risco em que viviam, era pra diminuir o próprio risco. Como? Tendo a posse de um documento legítimo de casados." (KUCINSKI, 2016, p. 45).

Também Ferreira (2020, p. 240) destaca que "Ana tinha o sobrenome 'Silva' pois se casara com Wilson Silva, colega de faculdade de Kucinski. Seu pai, Meir Kucinski, escritor de iídiche, nascido na Polônia, procurou reaver seu corpo, em vão.". Aspectos como os do casamento às escondidas da filha, a língua iídiche falada pelo pai e as comparações com a Polônia são ressaltados pelos leitores de $K$.: relato de uma busca porque de fato são assuntos que recebem ênfase também pelo autor Bernardo Kucinski, como acontece no capítulo Os extorsionários: "Mas na Polônia, embora a repressão fosse dura, quando prendiam, registravam, avisavam a família. Depois tinha julgamento. Havia acusação e defesa, visitas à prisão. Lá não sumiam com os presos." (KUCINSKI, 2016, p. 136). Kucinski compara os episódios da ditadura civil-militar com os acontecidos na Polônia e demais países em meio ao holocausto. Para Kucinski, entretanto, a ditadura civil-militar tornou-se terrível porque as vítimas sumiam, e os familiares ficavam sem saber o que exatamente aconteceu com os desaparecidos, imaginando o pior devido ao cenário de perseguição e tortura. Segundo Casarin (s.d., s.p.), leitor da obra de Kucinski,

A violência contra a família e contra Ana não se encerrou no desaparecimento em si. Depois disso, ela passou a ser tratada por muitos como uma mera comunista, como alguém que mereceu sofrer o que sofreu. Nem mesmo na USP, onde dava aulas, recebeu um tratamento respeitoso. Após uma decisão tomada por seus colegas, foi destituída de seu cargo por abandono de emprego, como se não ir ao trabalho fosse uma opção sua, não uma consequência de seu assassinato, de um crime político.

Em muitos casos de registros escritos de leitores de $K$.: relato de uma busca, não sabemos ao certo se eles se referem à obra ou àquilo que aconteceu na realidade à família de Kucinski. Um exemplo é o autor do trecho anteriormente citado, pois, em seu manifesto, o receptor da obra menciona o nome Ana, que sabemos ser na realidade a irmã de Bernardo Kucinski, mas na obra $K$.: relato de uma busca o nome dela não é revelado. São as verossimilhanças da obra com a vida da família 
de Kucinski que impulsionam os leitores a construir tais comparações e afirmações.

Aliás, ao verificarmos os comentários dos internautas da Skoob, a qual é denominada a maior rede social voltada aos leitores, uma das maiores ênfases dada por grande quantidade dos leitores de $K$.: relato de uma busca é justamente a busca do pai pela filha na narrativa e que isso é baseado na realidade vivida pelo pai de Bernardo Kucinski com relação à Ana, sua filha desaparecida. Muitos dos aspectos da vida da família Kucinski, tanto da vida pessoal quanto profissional, são enfatizados também pelos internautas da rede $S k o o b$, conforme podemos verificar no exemplo do comentário disposto na Figura 1.

Figura 1 - Trecho de comentário de internauta da $S k o o b$ a respeito do livro K.: relato de uma busca

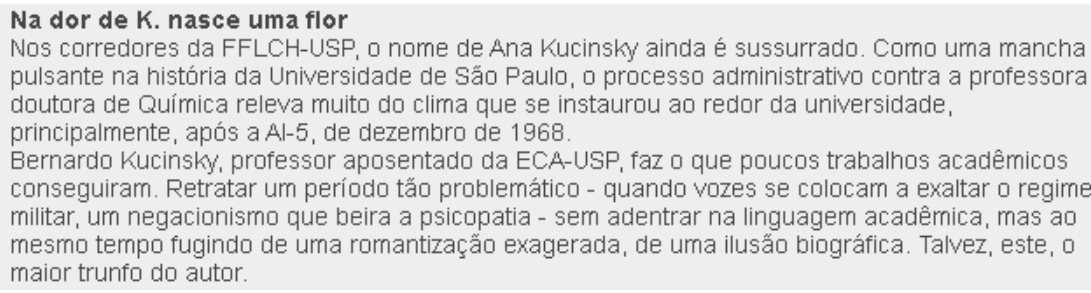

Fonte: SKOOB. https://www.skoob.com.br/livro/resenhas/207967/edicao:426975., 2021.

Conforme podemos verificar no trecho acima, Bernardo Kucinski consegue fazer o que poucos trabalhos acadêmicos conseguiram, que é retratar um período tão emblemático como a ditadura civil-militar. O autor de K.: relato de uma busca faz essa representação sem recorrer a uma linguagem rebuscada, e também faz com que sua narrativa não seja uma romantização piegas, o que, conforme verificamos no comentário do internauta da $S k o o b$, é provavelmente o maior acerto de Bernardo Kucinski. Também despertou nossa atenção o título do comentário desse internauta: "Na dor de K. nasce uma flor". Ao nosso ver, a flor, pelos indícios encontrados, é o próprio livro $K$.: relato de uma busca, que, mesmo retratando a ditadura civil-militar, um período tão traumático, e ao mesmo tempo protagonizar a história de um personagem idoso, que sofre, sensibiliza seus leitores, e faz com que estes se envolvam com os personagens e a história narrada. Esta "flor" que abdica da linguagem acadêmica e também de uma ilusão biográfica romantizada, conforme caracterizado pelo internauta da Skoob no segundo parágrafo, parte de informações verídicas, que aconteceram na realidade, conforme o leitor 
de $K$.: relato de uma busca ressalta anteriormente. Assim como demais internautas da $S k o o b$, também este relaciona o livro K.: relato de uma busca àquilo que aconteceu com Ana Rosa Kucinski, que é, como já evidenciamos antes, a irmã desaparecida do autor cuja obra estamos considerando para nossos estudos sobre a literatura contemporânea como lugar de resgate das memórias e luta contra o esquecimento dos episódios acontecidos em meados da ditadura civil-militar brasileira.

Ainda consoante o internauta da Skoob cujo trecho de seu comentário supracitamos, até na atualidade o nome de Ana Kucinski é sussurrado nos corredores da FFLCH-USP, universidade na qual ela lecionava e foi desligada após certo tempo de seu desaparecimento. Logo, o fato de Ana ter sido professora nessa universidade também é representado por Bernardo Kucinski em K.: relato de uma busca, principalmente o fato do desligamento dela injustamente: "Passaram-se dezenove meses desde o desaparecimento da filha de K., lotada nos quadros da universidade como professora assistente doutora. Na ordem do dia consta o processo 174 899/74 da reitoria pedindo a rescisão do seu contrato por 'abandono da função' [...]." (KUCINSKI, 2016, p. 142).

Outro fato destacado por leitores de K.: relato de uma busca é o de que desaparecidos na ditadura civil-militar seriam "homenageados" recebendo nomes de ruas, narrado no capítulo As ruas e os nomes: "A homenagem aos desaparecidos políticos em placas de rua tinha a função pedagógica de lembrar às futuras gerações a importância da democracia e dos direitos humanos." (KUCINSKI, 2016, p. 150). Esta passagem da obra K.: relato de uma busca é rememorada por Mügge (2016, p. 100):

No entanto, o narrador relata a ida de K. e de outros familiares de desaparecidos políticos a um evento no Rio de Janeiro, a um Loteamento denominado Vila Redentora, cujas ruas receberam, na ocasião, por iniciativa de um vereador de esquerda, o nome dos militantes mortos, quarenta e sete, no total.

Enquanto os nomes dos militantes desaparecidos foram destinados a ruas distantes, os de generais e outros nomes da elite foram destinados a ruas e pontes bem localizadas, com grande tráfego de pessoas, como é o caso da placa do viaduto General Milton Tavares: "Centenas de pessoas passam por aqui todos os dias, jovens, crianças, e leem esse nome na placa, e podem pensar que é um herói. Devem pensar isso. Agora ele entendia por que as placas com os nomes dos desaparecidos foram postas num fim do mundo." (KUCINSKI, 2016, p. 153).

Em linhas gerais, verificamos que estes vários elementos resgatados 
da realidade vivida pela família Kucinski em meio à ditadura civil-militar foram percebidos pelos leitores, pois eles estabeleceram as relações da ficção com o contexto real no qual está inserido. Essa relação do autor escrever para um público que recebe aquelas memórias passadas por Kucinski confirmam o papel ativo do leitor ressaltado por Figueiredo (2017) e que justamente este papel de recepção ativa e consequente propagação das memórias por meio da narrativa faz com que elas não se apaguem.

\section{CONSIDERAÇÕES FINAIS}

Em vista aos estudos e às análises que realizamos em nossos estudos, concluímos que diversos leitores de $K_{\text {.: }}$ relato de uma busca compreenderam que nessa narrativa estão guardadas memórias do autor e de sua família com relação a um período histórico traumático para milhares de pessoas, inclusive para eles. Diante desse sofrimento, o autor sentiu necessidade de compartilhar suas memórias a fim de que elas não fossem esquecidas e sentiu a necessidade de recorrer à literatura para resgatar e registrar essas memórias para que elas chegassem a mais pessoas. Dessa forma, Kucinski conseguiu escrever para outros e cumprir o que Ricoeur (2007) denominou de sentimento de dever.

Logo, a necessidade da lembrança do passado, do não esquecimento dele, conforme teorizado por Gagnebin (2006), vai ao encontro de inúmeros autores de narrativas que lutam contra o não esquecimento daquilo que aconteceu com eles e/ou familiares deles. Bernardo Kucinski, autor de K.: relato de uma busca, faz isso nessa obra, o que contribuiu para que ela fosse a escolhida para fins analíticos dos objetivos que aqui propomos. Afinal, ele faz uma rememoração do que aconteceu com sua irmã, com o intuito de manter viva a memória da irmã e também fazer o kaddish $^{3}$ dela.

No entanto, K.: relato de uma busca, assim como inúmeras outras narrativas que contém em suas páginas uma rememoração sobre a ditadura civil-militar, são também memórias de expectativas da contemporaneidade que tem tendências a um futuro. Através de suas narrações, esses autores pretendem, também, mudar o tempo posterior ao presente. Entrelaçamos a isso as palavras de Ricoeur (2007, p. 140), "os mundos dos predecessores e dos sucessores estendem nas duas direções do passado e do futuro, da memória e da expectativa, esses

3. É uma oração de louvor a Deus que enaltece seu nome e é recitado no lugar da pessoa falecida, e que aparece na obra K.: relato de uma busca. 
traços notáveis do viver juntos decifrados primeiro no fenômeno de contemporaneidade.".

Portanto, podemos concluir que $K .:$ relato de uma busca guarda em seu enredo uma trajetória de um pai em busca de sua filha perdida, sendo tais fatos baseados nas memórias de Bernardo Kucinski, autor da obra literária, fazendo com que ela seja integrante da literatura contemporânea voltada às narrações sobre o período da ditadura civil-militar. Além do mais, conforme percebemos, a narrativa $K$.: relato de uma busca ganhou destaque, conquistou aceitação de um considerável público e, sendo assim, contribui para que as memórias sejam preservadas e resgatem o passado, as tradições, as vidas e as imagens, conforme averiguamos em Gagnebin (2006). Sendo assim, a obra literária contemporânea K.: relato de uma busca é lida e compreendida como uma forma de resistência contra o esquecimento das memórias de Bernardo Kucinski e sua família.

\section{REFERÊNCIAS}

BEZERRA, Kátia da Costa. Que bom te ver viva: vozes femininas reivindicando uma outra história. Revista estudos de literatura brasileira contemporânea. n. 43. p. 35-48, jan/jun 2014. Disponível em: http://www.scielo.br/pdf/elbc/n43/03.pdf. Acessado em 13 de janeiro de 2019.

CASARIN, Rodrigo. Sobre como cuidar do passado. In: Jornal Literário da Companhia Editora de Pernambuco. Disponível em: https://suplementopernambuco.com.br/ pernambuco/70-perfil/1109-sobre-como-cuidar-do-nosso-passado.html. Acessado em 10 de julho de 2021.

FERREIRA, Arthur Barboza. Considerações sobre a narração em K.: relato de uma busca, de Bernardo Kucinski. In: Revista Versalete (ISSN 2318-1028) Curitiba, Vol. 8, $\mathrm{n}^{\circ} 14$, jan.jun. 2020. P. 238-251. Disponível em: http://www.revistaversalete.ufpr.br/edicoes/vol814/13-FERREIRA.-A.-B.-Considerac\%CC\%A7o\%CC\%83es-sobre-Kucinski-PRONTO. pdf. Acessado em: 10 de julho de 2021.

FICO, Carlos. Além do golpe: versões e controvérsias sobre 1964 e a Ditadura Militar. Rio de Janeiro: Record, 2004.

FIGUEIREDO, Eurídice. A literatura como arquivo da ditadura. Rio de Janeiro: 7 letras, 2017.

GAGNEBIN, Jeanne Marie. Lembrar escrever esquecer. São Paulo: Editora 34, 2006.

GAGNEBIN, Jeanne Marie. História e narração em Walter Benjamin. 2. ed. São Paulo: perspectiva, 1999.

KOEHLER, Adriano, Parede contra a dor. In: Rascunho: o jornal de literatura do Brasil. 
03 de novembro de 2012. Disponível em: http://rascunho.com.br/parede-contra-a-dor/. Acessado em 20 de maio de 2018.

KUCINSKI, Bernardo. K.: relato de uma busca. São Paulo: Companhia das letras, 2016.

MÜGGE, Ernani. K. - relato de uma busca: a ficção a serviço da revisão da história nacional. Signo [ISSN 1982-2014]. Santa Cruz do Sul, v. 41, n. nesp, jan./jun. 2016. p. 95-104. Disponível em: https://online.unisc.br/seer/index.php/signo/article/view/7331. Acessado em 10 de julho de 2021.

RICOEUR, Paul. A memória, a história, o esquecimento. Tradução de Alain François [et al.]. Campinas, SP: Editora da Unicamp, 2007.

SKOOB. https://www.skoob.com.br/livro/resenhas/207967/edicao:426975. Acessado em 13 de julho de 2021.

TAKETANI, Yasmin. Entrevista [Bernardo Kucinski]. In: Jornal Literário da Companhia Editora de Pernambuco. 05 de setembro de 2016. Disponível em: https://www. suplementopernambuco.com.br/entrevistas/1671-entrevista-bernardo-kucinski.html. Acessado em 10 de julho de 2021.

ZILLO, Mariana. K. - Relato de uma Busca é uma história da ditadura. In: Minasnerds. 17 de fevereiro de 2017. Disponível em: http://minasnerds.com.br/2017/02/17/k-relato-deuma-busca-e-uma-historia-da-ditadura/. Acessado em: 10 de julho de 2021.

RECEBIDO EM: 31/08/2021

ACEITE EM: 04/10/2021 